\title{
Immunologic Studies of the Old Yellow Enzyme. A Comparison between the Enzyme and Its Apoprotein
}

\author{
STEN KIST NER
}

Biochemical Department, Nobel Medical Institute, Stockholm, Sweden

\begin{abstract}
To achieve immunization rabbits were injected with preparations of Warburg's Old Yellow Enzyme (OYE) and its apoprotein. This resulted in the appearance of precipitating antibodies. The antigenantibody reaction was studied by means of quantitative precipitin reactions and agar gel diffusion experiments. Crude enzyme preparations were found to contain several antigenic components, on $\theta$ of which was identical with the crystalline enzyme. The precipitin reaction between crystalline OYE and antiserum showed a regular behaviour in excess antibody and equivalence zones, and after diffusion in agar gel one single precipitin line was formed. A comparison between OYE and its apoprotein showed an immunologic identity of the two proteins. The coenzyme, flavin mono-nucleotide, did not have hapten activity. The biologic significance of these findings is discussed.
\end{abstract}

$\mathrm{E}^{\mathrm{n}}$

nzymes, being proteins, may act as antigens. The resulting antibodies, in their reaction with the specific antigen, are often inhibitors of the catalytic activity. The inhibition of enzyme activity by antibodies is a mechanism of considerable biological interest, and has been the subject of a great number of investigations. Recent reviews have been published by Sevag ${ }^{1,2}{ }^{4}$, Marrack ${ }^{3}$ and Cinader ${ }^{4}$. The importance of the catalytic sites on the enzyme molecule in these antigen-antibody reactions has been emphasized. If these sites are identical with the sites of antigenic activity, the binding of antibody takes place here. Another possibility of inhibition arises when the antibodies couple to other parts of the enzyme molecule, causing steric blocking of the catalytic sites. In some instances precipitating antibodies with little effect on the enzyme activity in vitro have been obtained ${ }^{5}$. However, such antibodies may afford protection against the catalytic activity in vivo, probably because the antigenantibody complexes are rapidly removed from the circulation ${ }^{\mathbf{3}, \mathbf{5}, \mathbf{6}}$.

In many enzymes the catalytic activity is centered in a prosthetic or coenzyme group. These groups are often identical in widely different species. Antibodies formed to fit such groups might then cross-react with enzyme sys- 
tems in the immunized organism, causing a non-desirable condition of autoimmunization. It does not appear, however, that antibodies are produced against such structures, but rather against the species specific protein part of the molecule ${ }^{7,8}$. One would therefore not expect these coenzyme groups to act as haptens ${ }^{1}$.

Although much work has been done in this field, the role of the catalytic sites in different enzyme - antienzyme* systems has not yet been finally settled. Many difficulties prevent the study of the eventual participation of coenzyme groups as antigenic determinants. In most cases the interaction between coenzyme and the corresponding apoprotein is unknown, in other cases the reversibility of this reaction makes the immunologic studies erratic. The present work is a study of Warburg's "Old Yellow Enzyme» (OYE) using immunologic methods. This enzyme offers certain advantages for such an investigation. It can be prepared in a crystalline form ${ }^{9}$, and it has a molecular weight ${ }^{10}$ of about 104000 , suggesting good antigenic properties. The coenzyme group is flavin-mononucleotide (FMN), an isoalloxazin derivate, which may have the properties of a hapten. OYE contains 2 FMN molecules per mole ${ }^{9}$, which can easily be split off ${ }^{11}$, and thus the apoprotein is formed. The reaction

$$
\text { coenzyme }+ \text { apoprotein } \rightleftharpoons \text { enzyme }
$$

has been extensively studied by Theorell and Nygaard by fluorescence measurements ${ }^{12-14}$. The equilibrium is shifted far to the right, and thus the enzyme is rather stable, as well as the apoprotein in the absence of FMN.

\section{MATERIALS AND METHODS}

\section{Preparation of OYE and apoprotein}

$O Y E$ was prepared from brewer's bottom yeast **, using the method described by Theorell and Akeson ${ }^{9}$. The light absorption spectrum of crystalline OYE was in good agreement with that found by these authors. The enzyme was stored at $4^{\circ} \mathrm{C}$ under $80 \%$ saturated ammonium sulphate solution until used. To determine the amount of enzyme and the degree of purity in the different fractions, the light absorption at $464 \mathrm{~m} \mu$ was measured in a Beckman DU spectrophotometer. Using the value $\beta_{464}$ for $F M N=$ $2.43 \times 10^{7} \mathrm{~cm}^{2} /$ mole and FMN-content in OYE $=0.877 \%$, the amount OYE corresponding to this absorption could easily be calculated. Dry weight determinations were done on the same sample. The degree of purity was expressed as the ratio

$$
\text { amount enzyme found by light absorption }
$$

For the crystalline OYE this "purity index" was $1.00 \pm 0.05$.

Apoprotein was obtained after dissociation of the enzyme by the procedure of Warburg and Christian ${ }^{11}$. Thel solutions of apoprotein showed no light absorption corresponding to the $383 \mathrm{~m} \mu$ or $464 \mathrm{~m} \mu$ peaks of OYE or the $445 \mathrm{~m} \mu$ peak of FMN. The activity could be controlled and the concentration determined in a recording fluorescence meter by measuring the ability of the apoprotein to quench the fluorescence of FMN, as described

\footnotetext{
* In this paper the word "anti-enzyme" is used in the meaning: antibody against enzyme.

** Kindly supplied by Hamburgerbryggeriet, Stockholm.
}

Acta Chem. Scand. 12 (1958) No. 10 
by Theorell and Nygaard ${ }^{12}$. In all experiments where OYE and apoprotein were compared, the apoprotein was first prepared by cleaving the enzyme. The concentration was determined on a small aliquot of the solution. The rest was divided into two equal parts. FMN, slightly exceeding the equivalence, was added to one part, and a buffer blank to the other. Excess FMN was removed by dialysis. OYE thus obtained by dissociation and reassociation with FMN, showed the characteristic light absorption of the enzyme. The other solution contained an equivalent amount of apoprotein. All experiments were carried out in $0.15 \mathrm{M}$ sodium phosphate buffer, pH 7.4. The "titration" of apoprotein with FMN was done at room temperature.

FMN-solutions were made up from a commercial preparation (Sigma Chemical Company). A fresh solution was prepared the same day as the experiments were carried out and kept in the dark and the cold until used. The concentration was determined by measuring the light absorption ${ }^{9}$, using the value $\beta_{445}$ for $\mathrm{FMN}=2.81 \times 10^{7} \mathrm{~cm}^{2} / \mathrm{mole}^{*}$.

\section{I $m m u n$ ization}

Four male albino rabbits, 6 months old, weighing $2.5-3 \mathrm{~kg}$, were used for immunization. Rabbit No. 1 received 3 weekly i. m. injections of an enzyme preparation with purity index 0.20 . Each injection contained $60 \mathrm{mg}$ substance, as determined by dry weight, corresponding to $12 \mathrm{mg}$ of pure enzyme. For the other rabbits a Freund's adjuvant ${ }^{15,16}$ as described by Cohn ${ }^{17}$ was used. About 2/3 of the antigen were given in the first injection. Three weeks later the rest was injected i. m. without adjuvant as a booster dose. Rabbit No. 2 received $32 \mathrm{mg}$ of a preparation with purity index 0.70 (corresponding to $22 \mathrm{mg}$ of pure enzyme). For the last two rabbits an enzyme preparation with purity index 0.56 was used. The enzyme was dissociated, and one part of it reassociated with FMN. Each part contained $54 \mathrm{mg}$ (corresponding to $30 \mathrm{mg}$ of pure enzyme or the equivalent amount of apoprotein, respectively). Rabbit No. 3 received the OYE, and No. 4 the apoprotein.

Blood samples were collected by puncturing the central artery of the ear. Before immunization $10-12 \mathrm{ml}$ of blood were taken from each animal to obtain serum for control experiments. 7-10 days after the last injection the rabbits were anaesthetized and a cannula inserted into the left carotid artery. In this way 50-100 ml of blood were collected from each rabbit. The blood was allowed to clot at room temperature, and the clot retraction accomplished by incubation at $37^{\circ} \mathrm{C}$ for $30 \mathrm{~min}$. Serum was sucked off and stored at $-15^{\circ} \mathrm{C}$ in small aliquots. When used for experiments it was $1-3$ months old.

\section{Precipitin reactions}

The appearance of precipitating antibodies in the immune-sera was checked by ring tests ${ }^{18}$. Quantitative precipitin reaction ${ }^{10}$ was performed, using ultraviolet absorption spectroscopy to measure the precipitate ${ }^{20,21}$. Antigen solution in $0.15 \mathrm{M}$ sodium phosphate buffer pH 7.4 was mixed with $1 \mathrm{ml}$ serum. The volume was kept constant at $2.5 \mathrm{ml}$. The incubation time was $60 \mathrm{~min}$ at $37^{\circ} \mathrm{C}$, followed by $48 \mathrm{~h}$ at $4^{\circ} \mathrm{C}$. The precipitates were washed twice in saline in the cold and dissolved in $0.25 \mathrm{M}$ acetic acid ${ }^{21}$ to a volume of $3.0 \mathrm{ml}$. The absorption was read in a Beckman DU spectrophotometer at $277 \mathrm{~m} \mu$, where antigen as well as precipitate in acetic acid solution had a maximum. The extinction coefficient of the antigen had previously been determined. In excess antibody and equivalence zones the optical density of the antibody could be obtained by subtracting the optical density of antigen from that of the precipitate ${ }^{21}$.

Control experiments were run, using serum from the immunized animals, but collected before immunization.

* FMN Sigma contains some impuriries ${ }^{12}$. The apoprotein reacts, however, preferentially with the component identical with FMN from OYE 12-14. With FMN in excess, the OYE obtained in these association reactions could therefore be expected to be identical with the product obtained, when FMN from OYE is used.

Acta Chem. Scand. 12 (1958) No. 10 


\section{Electrophoresis}

Paper electrophoresis was performed, using Durrum's technique ${ }^{22}$, in barbiturate buffer $\mathrm{pH} 8.6$, ionic strength 0.075 , for $16 \mathrm{~h}$ at $100 \mathrm{~V}$, on $30 \mathrm{~cm}$ long Whatman No. 1 paper strips. Staining of proteins was done for $16 \mathrm{~h}$ in $0.01 \%$ bromophenol blue, the fractions were cut out, eluted in $0.01 \mathrm{~N} \mathrm{NaOH}$, and the absorption read at $590 \mathrm{~m} \mu^{22}$. To correct for different uptake of stain by albumins and globulins, the values obtained for globulins were multiplied by 1.3 .

\section{Antigen-antibody reactions in agar gel}

The technique described by Ouchterlony was used ${ }^{23}$. The gel contained $1.5 \%$ agar, $0.15 \mathrm{M}$ sodium phosphate buffer $\mathrm{pH} 7.4$, and merthiolat 1:10000. The reactions were performed in sealed Petri dishes. A $50 \times 50 \mathrm{~mm}$ glass plate was placed in the bottom of each dish under the agar ${ }^{24}$. Antigen and antibody were added in concentrations close to their equivalence ratio. Incubation was done at $4^{\circ} \mathrm{C}$, room temperature, or $37^{\circ} \mathrm{C}$ for different periods of time. In some experiments the basins were refilled 2 or 3 times, each filling consisting of $0.15-0.20 \mathrm{ml}$. After the reactions were completed, the gel was washed in saline, distilled water, and finally dehydrated with ethyl alcohol ${ }^{24}$. The gel was cut along the sides of the glass plate and allowed to dry at room temperature ${ }^{25}$. In this way a thin film containing the precipitin lines was obtained on the glass plate. These preparations were stained for 20-30 min in a solution of azocarmine B containing $10 \%$ acetic acid and $50 \%$ methyl alcohol. Excess stain was removed by washing the film in the solvent. After this procedure the precipitin lines showed a strong red colour, whereas the rest of the film was practically without colour.

Buffer solutions of OYE and apoprotein were used as antigens. They were tested against sera from the immunized animals, collected before and after immunization. 1/10 volume EDTA-solution ( $1 \mathrm{~g}$ sequestrene- $\mathrm{Na}_{2}$ and $0.7 \mathrm{~g} \mathrm{NaCl}$ per $100 \mathrm{ml}$ solution) was added to all sera. In absorption experiments different amounts of OYE or apoprotein were added in the basins containing serum. Absorbed sera were tested against OYE and apoprotein solutions. All experiments were run in duplicate.

\section{RESULTS}

Precipitating antibodies were found in the serum of all animals on the 4th week of immunization. In rabbits receiving adjuvant, antibodies appeared even before the booster-dose was given. Paper electrophoresis of the sera showed a relative decrease of the albumin fraction and increase of globulin fractions, especially $\beta$ and $\gamma$, following immunization in all animals. These changes were essentially the same, regardless of the technique of immunization, and whether OYE or apoprotein was used as antigen.

Quantitative studies of the precipitin reaction showed a regular behavior of the OYE-anti-OYE system in excess antibody and equivalence zones. Plotting the amount of antigen added against the amount of precipitate formed gave a parabolic curve. When, according to the equation of Heidelberger and Kendall ${ }^{19}$, the amount of antigen added was plotted against the ratio

$$
\frac{\text { antibody precipatated }}{\text { antigen precipitated }}
$$

a straight line was obtained. Curve A of Fig. 1 shows the results, when a crystalline preparation of OYE was tested against an anti-OYE serum. In excess antigen zone there is a rather slow decline of the curve. Even in large

Acta Chem. Scand. 12 (1958) No. 10 


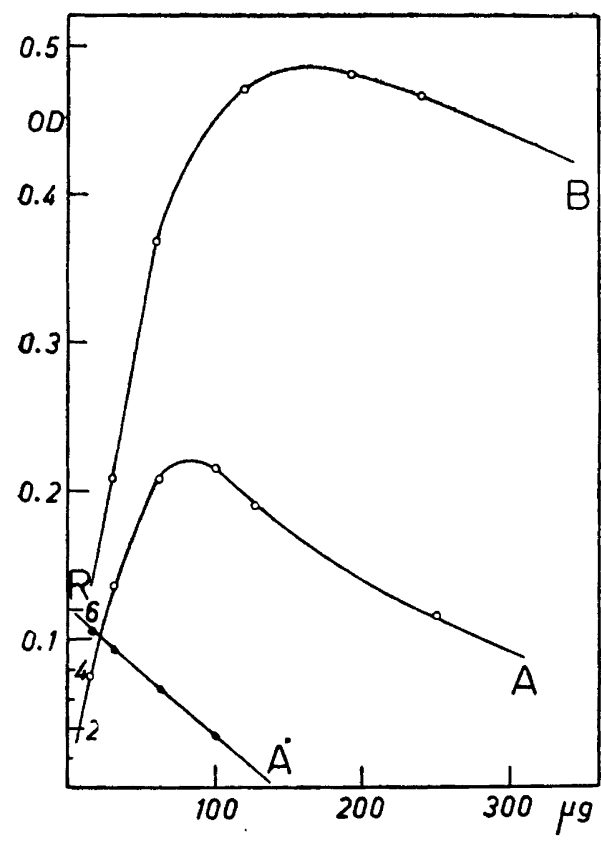

Fig. 1. Quantitative precipitin reaction. Anti-OYE serum from a rabbit, immunized with a total of $54 \mathrm{mg}$ of an enzyme prepa. ration with purity index 0.56 (No. 3). Curve A shows the reaction with crystalline OYE, purity index 0.97 , as antigen. $A^{\prime}$ is the corresponding line, obtained by plotting the amount of antigen added against $\mathbf{R}\left(\frac{\text { antibody precipitated }}{\text { antigen precipitated }}\right)$. In $\mathbf{B}$ the antigen is an enzyme preparation with purity index 0.52. See text.

excess antigen, i.e. 5 times as much as the amount needed to reach the equivalence zone, there was a small precipitate formed. This behaviour of the system will be further commented on in the discussion. The reaction did not show the same regularity when an impure enzyme preparation was tested against the same serum. Also, the equivalence point was moved towards higher concentrations of antigen, (Curve B, Fig. 1). The antigen in this case contained about $50 \%$ OYE, and about twice as much as of crystalline OYE was needed to reach the equivalence point. This did not, however, indicate that OYE was the only reacting antigen, since the precipitate formed was much larger ${ }^{26}$. In this latter case the decline of the curve in the antigen excess area was even less pronounced than in the reaction, where crystalline enzyme was used as antigen.

Hapten reactions ${ }^{18}$ were performed in the equivalence zone, using crystalline OYE as antigen. The antiserum was incubated with FMN before adding the enzyme. The concentration of FMN was determined on the basis of the amount of OYE taking part in the reaction. Thus, in different experiments incubation with 1 to 20 moles of FMN per mole of OYE was tried. In no case did the presence of FMN reduce the formed precipitate significantly nor was a precipitate formed when FMN alone was incubated with antiserum.

When crystalline OYE reacted with anti-OYE serum after diffusion in agar gel, only one precipitine line was formed, whereas impure preparations caused the appearance of several lines. The two antigen solutions were tested simultaneously against the same serum, using agar plates with 3 basins, as 


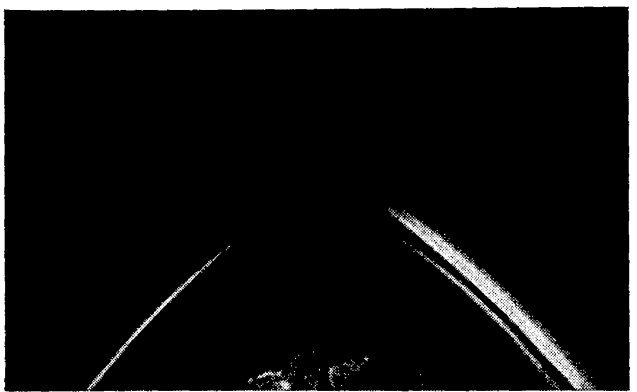

Fig. 2. Antigen-antibody reaction in agar gel. The gel contained 3 basins, arranged as described in Ref. ${ }^{23}$. Antigens and antiserum were the same as in the experiments illustrated in Fig. 1. The upper left basin contained the crystalline OYE, $0.1 \mathrm{mg} / \mathrm{ml}$, the upper right contained the impure enzyme, $0.2 \mathrm{mg} / \mathrm{ml}$, and the lower basin contained the anti-OYE serum. The basins were filled 4 times. Incubation at $37^{\circ} \mathrm{C}$. Lines appeared after $24-36 \mathrm{~h}$. Note the fusion of the single line on the left side, representing the reaction between the crystalline OYE and antiserum, into one of the 4 lines on the right side (crossing the first and completely fusing into the second line from the left).

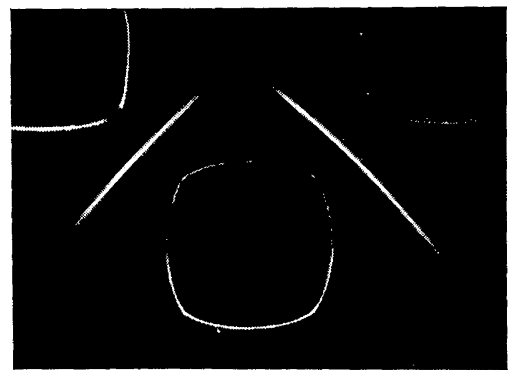

Fig. 3. Antigen-antibody reaction in agar gel. Anti-OYE serum in the lower basin tested against an OYE-preparation (purity index $0.60,0.15 \mathrm{mg} / \mathrm{ml}$ ) in the upper left basin and the equivalent apoprotein solution in the upper right. The basins were filled three times. Incubation at $37^{\circ} \mathrm{C}$. Three lines appeared on each side of the serum basin after $24-36 \mathrm{~h}$, forming $\mathrm{a}$ symmetric pattern, with the lines on one side fusing into those on the other side.

described in Ref ${ }^{23}$. Crystalline OYE was added in one basin, a crude enzyme preparation in another, and antiserum in the middle. The line formed between the crystalline enzyme and antiserum fused into one of the lines formed between the crude enzyme and serum. Fig. 2 is a photograph of such an experiment, where antigens and antiserum tested were the same as those in the quantitative precipitin reactions illustrated in Fig. 1. Similar results were obtained with all anti-OYE sera. Incubation at lower temperatures did not alter the results, although a longer time was necessary for the lines to develop. Leaving the plates at $4^{\circ} \mathrm{C}$ for several weeks did not result in the appearance of more precipitin lines. Negative results were consistently obtained in these experiments when sera from the immunizied animals, collected before immunization, were tested.

Different preparations of OYE were compared with corresponding apoprotein solutions (see Material and Methods, 1) in similar experiments. The pattern of lines between OYE and anti-OYE serum was identical with that between apoprotein and the same serum, and the lines on one side fused into those on the other side (Fig. 3). When crystalline OYE and apoprotein, obtained after cleaving the crystalline enzyme, were tested, one line was formed on each side of the serum basin (Fig. 4). When the same experiments were repeated using anti-apoprotein serum, the results were identical with those obtained with anti-OYE serum. 


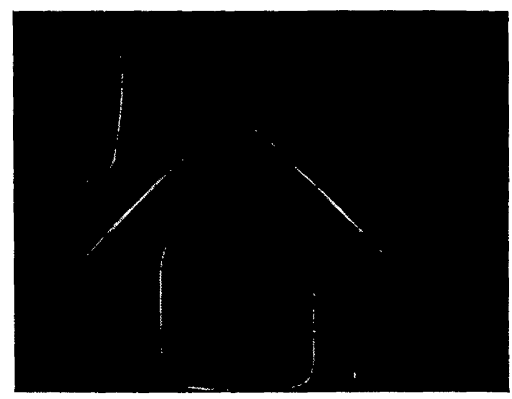

Fig. 4. Antigen-antibody reaction in agar gel. Anti-OYE serum in the lower basin tested against a solution of crystalline OYE, $0.1 \mathrm{mg} / \mathrm{ml}$, in the upper left basin, and an equivalent solution of apoprotein in the upper right. The basins were filled 4 times. Incubation at $37^{\circ} \mathrm{C}$. The lines appeared after $24 \mathrm{~h}$. An identical result was obtained when the same antigens were tested against an anti-apoprotein serum.

A rough estimation of the sensitivity of the agar gel diffusion technique was done when $10 \mu \mathrm{g}$ of crystalline OYE were tested against the equivalent amount of serum, as found by quantitative precipitin reaction. A clearly visible line was obtained.

Anti-OYE and anti-apoprotein serum from rabbits Nos 3 and 4 were tested after absorption with antigen. Only crystalline OYE and apoprotein from crystalline OYE, respectively, were used in these experiments. The equivalence point of each serum with the homologous antigen was determined. Serum and the equivalent amount of antigen were mixed in one basin in an agar plate and tested against OYE and apoprotein. Antigens, used for absorption, were then reversed, i.e. anti-OYE serum was absorbed with apoprotein and vice versa. In no experiment did the absorbed serum retain the ability to react with either OYE or apoprotein. The two antigens seemed able to replace each other, and to absorb homologous as well as heterologous serum.

\section{DISCUSSION}

Attempts to immunize rabbits with preparations of OYE have previously been made by Várterész and Kesztyüs ${ }^{27}$. The antigen used was a crude enzyme preparation. These workers found no precipitating or complement fixating antibodies, nor was the activity of the enzyme inhibited by the antiserum. Their conclusion was that OYE lacks antigenic properties, possibly due to identical structure in different species. This opinion clearly differs from the common concept of protein specificity, and has also been criticized ${ }^{1,28}$. Considering later investigations it appeared even more probable that antibodies against OYE could be obtained, since immunization with crystalline yeast enzymes had been successful ${ }^{29,30}$. Results of the present work show that crude preparations of OYE contain several antigenic components. One of these is evidently identical with the crystalline OYE.

When crystalline OYE reacted with anti-OYE serum, a precipitate was formed. Quantitative studies showed a regularity of this reaction in excess antibody and equivalence zones, suggesting a single antigen-antibody system ${ }^{\mathbf{2 6}}$. There was still a precipitate formed in rather large excess antigen. This may be an indication of impurities in the antigen, or of cross-reactions with several antibodies. Certain antigens, however, although of somewhat different type, 
have been described to cause this type of reaction (see Ref ${ }^{26}$ ). Also, in this particular case the method employed influenced the curve. At the wave length where the precipitates were measured, the extinction coefficent of crystalline OYE is higher than that found for different rabbit antibodies ${ }^{21}$. Precipitates formed in excess antigen thus caused a relatively high absorption. - A careful analysis of the quantitative precipitin reaction was not done because of the shortage of material. It was mainly employed to determine optimum reaction conditions for other experiments.

The reaction between crystalline OYE and anti-OYE serum in agar gel diffusion experiments resulted in a single precipitin line. This is an indication of antigenic homogeneity of the material. Also it appeared that the precipitate was the result of the reaction between enzyme and specific antibody. A cross reaction with some other yeast protein antibodies was not likely, since the precipitin line fused into an identical line on the site of reaction between antiserum and crude enzyme, which contained the same concentration of pure OYE as did the crystalline preparation (Fig. 2). The existence of an eventual homologous antigen in this area would have prevented a cross reaction to occur here ${ }^{31,32}$, and the line between the crystalline enzyme and serum on the left side would probably have shown partial coalescence ${ }^{33}$ into the line representing the reaction between the homologous antigen and serum on the right side. The complete fusion of the two lines into an are that now occurred is evidence of identical antigen on both sides ${ }^{23,33}$. The same antigen diffused from the basins containing crystalline and crude enzyme.

OYE and apoprotein showed same reactivity with anti-OYE as well as anti-apoprotein serum. Both sera were equally absorbed with any one of these antigens. Also, FMN did not have the effect of a hapten. The enzyme and its apoprotein were identical from the immunologic point of view. The coenzyme group was apparently not engaged in the antigenic active part of the enzyme molecule or in the binding to antibody.

It may be asked whether injection of OYE and apoprotein into the animals actually ment the introduction of two different antigens. Injected OYE could hardly have dissociated to any great extent because of the firm association between FMN and apoprotein*. On the other hand, it may be postulated that injected apoprotein associates with free FMN in vivo to form flavoprotein. If this is true, apoprotein, for all practical purposes, is immunologically identical with OYE. Such an association could not be assumed to take place in the in vitro experiments. The assumption that the coenzyme group does not take part in the immunologic active part of the enzyme molecule therefore appears to be valid. The biologic importance of this finding has already been discussed in the introduction. Production of antibodies reacting with structures common to the immunized organism, does not seem beneficial. Antibodies against the

\footnotetext{
* The equilibrium constant in the dissociation reaction of OYE has been determined by Theorell and Nygaard. It was found to be around $0.7 \times 10^{-8}$ in a buffer of $\mathrm{pH} 5.75$, containing $0.25 \mathrm{M}$ Na-phosphate and $0.4 \mathrm{M} \mathrm{NaCl}^{12}$. At pH around 7 and lower $\mathrm{Cl}^{-}$the constant is considerably decreased ${ }^{13}$. It is therefore very unlikely that injected OYE dissociated to any notable extent. At least this could not be true in rabbit No. 1, which was immunized with injections of enzyme without adjuvant, and results with immune serum from this rabbit were in good agreement with those obtained with serum from the other animals.
}

Acta Chem. Scand. 12 (1958) No. 10 
enzyme may still inhibit the activity. This problem is presently under investigation. It is possible, however, that replacement of the coenzyme group with some structually related compound, as perhaps happens in chemotherapy ${ }^{34}$, may alter the antigenic behaviour of the enzyme.

Acknowledgement. The author wishes to express his thanks to Professor Hugo Theorell and coworkers at the Department of Biochemistry, Nobel Medical Institute, for valuable discussions and advices during the course of this work.

\section{REFERENCES}

1. Sevag, M. G. Immuno-Catalysis, Charles C. Thomas Publ., Springfield 1945.

2. Sevag, M. G. Ergeb. Hyg. Bakteriol. Immunitätsforsch. u. Exptl. Therap. 28 (1954) 424.

3. Marrack, J. R. in Sumner, J. B. and Myrbäck, K. The Enzymes, Vol. I, Part 1, Academic Press Inc., New York 1950, p. 343.

4. Cinader, B. Ann. Rev. Microbiol. 11 (1957) 371.

5. Kirk, J. S. J. Biol. Chem. 100 (1933) 667.

6. Kirk, J. S. and Sumner, J. B. J. Biol. Chem. 94 (1931) 21.

7. Heidelberger, M. and Landsteiner, K. J. Exptl. Med. 38 (1923) 561.

8. Bonnichsen, R. K. Arch. Biochem. 12 (1947) 83.

9. Theorell, H. and Ákeson, Å. Arch. Biochem. Biophys. 65 (1956) 439.

10. Ehrenberg, A. Acta Chem. Scand. 11 (1957) 1257.

11. Warburg, O. and Christian, W. Biochem. Z. 298 (1938) 368.

12. Theorell, H. and Nygaard, A. Acta Chem. Scand. 8 (1954) 877.

13. Theorell, H. and Nygarard, A. Acta Chem. Scand. 8 (1954) 1649.

14. Nygaard, A. and Theorell, H. Acta Chem. Scand. 9 (1955) 1587.

15. Freund, J. and McDermott, K. Proc. Soc. Exptl. Biol. Med. 49 (1942) 548.

16. Freund, J. and Walter, W. W. Proc. Soc. Exptl. Biol. Med. 56 (1944) 47.

17. Cohn, M. in Methods in Medical Research Vol. 5, p. 271, The Year Book Publ. Inc., Chicago 1952.

18. Kabat, E. A. and Mayer, M. M. Experimental Immunochemistry, Charles G. Thomas, Springfield 1948.

19. Heidelberger, M. and Kendall, F. E. J. Exptl. Med. 61 (1935) 563.

20. Eisen, H. N. J. Immunol. 60 (1948) 77.

21. Gitlin, D. J. Immunol. 62 (1949) 437.

22. Block, R. J., Durrum, E. L. and Zweig, G. A Manual of Paper Chromatography and Paper Electrophoresis, 2nd Ed. Academic Press Inc. Now York 1958.

23. Ouchterlony, Ö. Arkiv Kemi, Mineral. Geol. 26B (1948) No. 14.

24. Perlman, P. and D'Amelio, V. D. Nature 181 (1958) 491.

25. Uriel, J. and Grabar, O. Ann. inst. Pasteur 90 (1956) 427.

26. Cohn, M. in Methods in Medical Research Vol. 5, p. 301, The Year Book Publ. Inc., Chicago 1952.

27. Várterész, W. and Kesztyüs, L. Z. Immunitätsforsch. 99 (1941) 211.

28. Landsteiner, K. The Specificity of Serological Reactions, Harvard University Press, Cambridge 1947.

29. Najjar, V. A. and Fisher, J. Science 122 (1955) 1272.

30. Antoni, F. and Keleti, T. Nature 179 (1957) 1020.

31. Mayer, M. and Heidelberger, M. J. Biol. Chem. 143 (1942) 567.

32. Cohn, M. and Torriani, A. M. J. Immunol. 69 (1952) 471.

33. Oudin, J. in Methods in Medical Research, Vol. 5, p. 335, The Year Book Publ. Inc. Chicago 1952.

34. Haas, E. J. Biol. Chem. 155 (1944) 321.

Received August 22, 1958. 